University of Northern lowa

UNI ScholarWorks

Graduate Research Papers

Student Work

2008

\title{
Alcohol use among adolescents
}

Malynda R. Zuck

University of Northern lowa

Let us know how access to this document benefits you

Copyright (C2008 Malynda R. Zuck

Follow this and additional works at: https://scholarworks.uni.edu/grp

Part of the Educational Leadership Commons

\section{Recommended Citation}

Zuck, Malynda R., "Alcohol use among adolescents" (2008). Graduate Research Papers. 1790.

https://scholarworks.uni.edu/grp/1790

This Open Access Graduate Research Paper is brought to you for free and open access by the Student Work at UNI ScholarWorks. It has been accepted for inclusion in Graduate Research Papers by an authorized administrator of UNI ScholarWorks. For more information, please contact scholarworks@uni.edu. 


\title{
Alcohol use among adolescents
}

\begin{abstract}
Alcohol is the most frequently used drug among adolescents today. Alcohol use among adolescents has been linked to many probable consequences and risks including: motor vehicle crashes, risky sexual behavior and an increased risk for sexually transmitted diseases, suicide, poor physical and mental health, lower social competence, and decreases in school achievement (Brown et al., 2007; Diego, Field, \& Sanders, 2003; Wallace \& Fisher, 2006). Research has shown that the earlier an adolescent initiates with the use of alcohol, the more likely that person will experience alcohol dependence in his or her life, with the onset of dependence occurring quickly and at younger ages (Brown et al., 2007; Brown, Catalano, Fleming, Haggerty, \& Abbott, 2005; Diego et al., 2003; Hingson, Heeren, \& Winter, 2006). Despite these risks, many adolescents continue to moderately consume alcohol. This paper will identify variables contributing to an adolescent's choice of whether or not to use alcohol, state the possible effects of teen alcohol use, and present implications for school counselors, including effective prevention and treatment interventions for working with adolescents.
\end{abstract}




\title{
ALCOHOL USE AMONG ADOLESCENTS
}

\author{
A Research Paper \\ Presented to \\ The Department of Educational Leadership, Counseling, \\ and Postsecondary Education \\ University of Northern Iowa \\ In Partial Fulfillment \\ of the Requirements for the Degree \\ Master of Arts in Education \\ by \\ Malynda R. Zuck
}

May 2008 
This Research Paper by: Malynda R. Zuck

Entitled: ALCOHOL USE AMONG ADOLESCENTS

has been approved as meeting the research paper requirements for the Degree of Master of Arts in Education.

Mand 20, 2008

Date Approved

April 7, 20:8

Date Received

\section{J. Bartlett}

Adviser/ Director of Research Paper

\section{Michael D. Waggoner}

Head Department of Education Leadership,

Counseling, and Postsecondary Education 


\begin{abstract}
Alcohol is the most frequently used drug among adolescents today. Alcohol use among adolescents has been linked to many probable consequences and risks including: motor vehicle crashes, risky sexual behavior and an increased risk for sexually transmitted diseases, suicide, poor physical and mental health, lower social competence, and decreases in school achievement (Brown et al., 2007; Diego, Field, \& Sanders, 2003; Wallace \& Fisher, 2006). Research has shown that the earlier an adolescent initiates with the use of alcohol, the more likely that person will experience alcohol dependence in his or her life, with the onset of dependence occurring quickly and at younger ages (Brown et al., 2007; Brown, Catalano, Fleming, Haggerty, \& Abbott, 2005; Diego et al., 2003; Hingson, Heeren, \& Winter, 2006). Despite these risks, many adolescents continue to moderately consume alcohol. This paper will identify variables contributing to an adolescent's choice of whether or not to use alcohol, state the possible effects of teen alcohol use, and present implications for school counselors, including effective prevention and treatment interventions for working with adolescents.
\end{abstract}




\section{Alcohol Use among Adolescents}

Adolescents today are growing up in a high pressure society in which they are making decisions daily which will likely affect their future paths. Choosing whether or not to engage in the use of alcohol is one of such decisions. Alcohol is the drug most frequently used by adolescents, and its use carries with it a knapsack of probable consequences and risks (Arta, Stafford, \& Tims, 2003; Brown, Teufel, Birch, Raj, Inzenberg, Lyness, \& Kancherla, 2007). Alcohol use among adolescents has been linked to motor vehicle crashes, risky sexual behavior and an increased risk for sexually transmitted diseases, suicide, poor physical and mental health, lower social competence, and decreases in school achievement (Brown et al., 2007; Diego, Field, \& Sanders, 2003; Wallace \& Fisher, 2006). It is also associated with problems in adulthood including marital discord, interpersonal problems, and limited career opportunities (Wallace et al., 2006). Research has shown that the earlier an adolescent initiates with the use of alcohol, the more likely that person will experience alcohol dependence in his or her life, with the onset of dependence occurring quickly and at younger ages (Brown et al., 2007; Brown, Catalano, Fleming, Haggerty, \& Abbott, 2005; Diego et al., 2003; Hingson, Heeren, \& Winter, 2006).

Despite these risks, many adolescents continue to moderately consume alcohol. According to a 2005 national survey, three-fourths of $12^{\text {th }}$ graders, more than two-thirds of $10^{\text {th }}$ graders, and about two in every five $8^{\text {th }}$ graders have consumed alcohol, and of those statistics $11 \%$ of $8^{\text {th }}$ graders, $22 \%$ of $10^{\text {th }}$ graders, and $29 \%$ of $12^{\text {th }}$ graders had engaged in heavy, or binge, drinking within the past two weeks (Johnston, O'Malley, Bachman, \& Schulenberg, 2006). This paper will identify variables contributing to an 
adolescent's choice of whether or not to use alcohol, state the possible effects of teen alcohol use, and present implications for school counselors, including effective prevention and treatment interventions for working with adolescents.

\section{Influences}

\section{Peer Variables}

During early adolescence, friendships are no longer predominantly one-to-one, but begin to expand into larger, more autonomous social networks (Brown et al., 2007). Adolescents are likely to form cliques, groups of friends who dress similarly and engage in activities together (Papalia, Olds, \& Feldman, 2007). Membership into a clique is many times based on social status and popularity. These cliques can be great for some children, but they are often a form of stress and problems for others. Peers play an important part of early adolescence, and the influence can be positive or stressful, depending on the type of friendships and intimacy of them.

Susceptibility to peer pressure. Peers can be a great form of support for children, but they can also be a source of humiliation (Vernon, 2004). Adolescents often perceive themselves as the center of attention, experiencing the sense of an imaginary audience and increasing their vulnerability to others' perceptions and views due to their fear of rejection, disapproval, and negative feedback (Vernon \& Clemente, 2005). Early adolescents often times give into peer pressure in order to fit in and avoid disapproval from their peers (Papalia, et al., 2007). A study conducted by Arta et al. (2007) found that problem drinkers are more susceptible to peer pressure to use alcohol than moderate or non-drinkers. Yet other studies suggest peer pressure not to use alcohol is more common than peer pressure to use it (Brown et al., 2007; Wallace et al., 2006). 
Peer norms. Adolescents often times overestimate the number of their peers who engage in alcohol use, with problem drinkers perceiving their peers to drink more compared to non-drinkers (Arta et al., 2007). Perceived alcohol use among peers was predictive in whether or not an adolescent engaged in the experimentation of alcohol (Brown et al., 2007). Furthermore, adolescents were more likely to engage in alcohol use if their peer group was also involved (Beman, 1995; Brown et al., 2007; Wallace et al.,2006). Adolescents reported social needs (fitting in, being popular, being cool, acquiring friends, and gaining attention) and enjoyment (liking the feeling of being high and having fun) as reasons to engage in alcohol use with peers (Beman, 1995).

\section{Parental Variables}

During early adolescence, children begin to push for autonomy from their parents and search to define themselves (Vernon, 2004). Children need to explore in order to achieve a self-identity. Early adolescents do hold their parents' values and beliefs, but need to explore to define each of them for themselves. Therefore, although adolescents are seeking a self-identity and may do so through alcohol use and experimentation, their parents' beliefs and values still help to influence their decisions.

Parental use of alcohol and approval of alcohol use. In families where alcohol use is common, adolescents are 2.5 times more likely to use and experiment with alcohol than those whose parents model less frequent use (Beman, 1995; Brown et al., 2007). Access to alcohol may contribute to this statistic (Brown et al., 2007). Children's alcohol norms seem to model their parents' norms. Adolescents with parents who are disapproving of high risk behaviors, such as adolescent alcohol use, are more likely to disapprove of substance use themselves (Wallace et al., 2006). 
Parental monitoring and support. Studies have found that adolescents whose parents demonstrate low levels of control and support present higher rates of alcohol use (Arta et al., 2003; Brown et al., 2007; Jackson et al., 2006; Power, Stewart, Hughes, \& Arbona, 2005). Furthermore, adolescents are more likely to become substance users if they come from dysfunctional or disturbed families (Beman, 1995). However, adolescents involved in a positive parent-child relationship are less likely to display sensation seeking behaviors, including early adolescent alcohol use (Brown et al., 2007). Brown et al. (2007) suggests that "proactive family management may also indirectly inhibit alcohol initiation" (p. 2). Greater parental involvement in the adolescent's life may help to discriminate against the initiation and experimentation of alcohol. More parental monitoring, greater parental communication, and higher expectations of negative consequences all help to deter adolescent alcohol use (Arta et al., 2003; Brown et al., 2007; Bryant \& Zimmerman, 2002; Thorlindsson \& Bernburg, 2006). Studies have also found that family oriented adolescents are much more likely to abstain from alcohol (Hoel, Erikson, Breidablik, \& Meland, 2004).

\section{Academic Variables}

Academic variables provide some of the strongest predictors for adolescent alcohol use. Yet, some of these same predictors can be viewed as the most significant protective factors as well. Regardless of one's view, it is clear that academics play an important role in an adolescent's choice to use alcohol.

Grades and academic skills. Regular alcohol use contributes to academic failure. Adolescents who regularly use alcohol performed significantly lower on standardized test in contrast to their peers (Cox, Zhang, Johnson, \& Bender, 2007; Diego, Field, \& 
Sanders, 2003). The link of causality is questioned however. Some researchers believe that academic problems precede alcohol use and students initiate or accelerate with substance-use behaviors as a way to cope with academic failure (Cox et al., 2007). It is debatable and unlikely however, that a student's dissatisfaction with his or her grades alone increases his or her use with alcohol. Poor academic achievers are more likely to skip school, engage in delinquent behavior leading to disciplinary problems, and associate with other deviant peers, and the combination of these choices creates a high risk environment for an adolescent, often encouraging and contributing to an increase in alcohol use (Cox et al., 2007). Academic performance declines with elevated levels of substance use, and this can largely be contributed to an adolescent's reduction in academic motivation.

Motivational factors. An adolescent's motivational beliefs directly influence his or her academic engagement. Adolescents' beliefs about the importance of academics as well as beliefs regarding their own ability and academic expectations are linked to how much they engage in binge drinking (Bryant \& Zimmerman, 2002). Some adolescents may use heavy drinking to compensate for their low motivation and academic frustration, whereas others with little problems in academic achievement may engage in alcohol use as a means to engage socially with others. Therefore, low motivation among high achieving students indicates a risk for alcohol use. High grades are considered a protective factor, however it is only the combination of high grades and high motivation that protects youth from the increased pressures of alcohol use as they progress through high school (Bryant \& Zimmerman, 2002). 
Attachment to school. Students who have an attachment to school are less likely to use or abuse alcohol. Students who participate in sports or other extra curricular activities are less likely to use alcohol and drugs, and their association with alcohol- and drug-using peers weakens as well, putting them in less risk (Thorlindsson \& Bernberg, 2006). However, students do not need to participate in extra curricular activities in order to feel connected to their school. A study conducted by Henry and Slater (2007) found that students' association with deviant behavior is less when the students identify with the norms and goals of the school. Furthermore, "when the school environment is pleasant, there are positive bonds between students and teachers, faculty and students regularly participate in activities together, students frequently serve in leadership roles, and students are high achievers" (Henry \& Slater, 2007, p. 74). Students who attend schools that create a positive environment and display a strong sense of community will have fewer alcohol related issues (Henry \& Slater, 2007).

Societal Variables and the Influence of Media

Adolescents receive mixed messages from society affecting their attitude toward drinking and drug use (Beman, 1995). Many of these messages come in the form of entertainment programming and advertisements. Alcohol is the most common beverage shown on television, and its use is prevalent in prime-time programming, music videos, and during television coverage of college and professional sporting events (Robinson, Chen, \& Killen, 1998; DuRant, Rome, Rich, Allred, Emans, \& Woods, 1997). Programs and advertisements depicting or advocating alcohol use are often glorified and presented in an attractive, positive, and provocative way, void of negative consequences (Robinson et al., 1998; DuRant et al., 1997). According to a study conducted by Robinson, Chen, 
and Killen (1998), "Television viewing and music videos, with their high content of positive alcohol portrayals and advertising, are particularly strong risk factors for the onset of drinking in adolescents,” (p. 62). For adolescents, television is their leading source for information about drugs and alcohol, and given the fact that many advertisements and programs are absent of negative consequences, it is likely television exposure increases the likelihood of adolescent alcohol use (DuRant et al., 1997).

\section{Effects of Alcohol Use among Adolescents}

Adolescence is a time of great development: physically, emotionally, and intellectually. Although adolescents' bodies may be fully developed by the age fifteen, making them look like adults, they are still physiologically underdeveloped.

Adolescents' prefrontal cortex, the area of the brain which controls advanced cognition, including abstract thought, judgment of consequences, planning, and controlling of impulses, is still developing and growing well into their 20's (Papalia et al., 2007).

Alcohol use among adolescents impairs their already faulty judgment, contributing to their increased risk of accidental death (largely resulting from motor vehicle crashes), homicide, suicide, sexually transmitted infections, and teen-age pregnancy, as well as juvenile delinquency and other criminal behavior (Eaton et al., 2004). Adolescents who use alcohol may also experience impaired physical, social, and mental development (Eaton et al., 2004). In fact, Hoel et al. (2004) found that moderate and heavy drinkers report greater problems in their relations with school and parents than those who abstain or drink lightly. Hoel et al. (2004) also found that emotional and psychosomatic problems increased as adolescents' alcohol consumption increased. Thus, 
abstainers and light drinkers appear emotionally healthier, succeeding to a greater extent in a variety of social arenas (Hoel et al., 2004).

Early initiation rates increase the risk of a lifetime of dependency (Brown et al., 2007; Brown etal., 2005; Diego et al., 2003; Hingson et al., 2006). Therefore, adolescents who choose to use alcohol will likely be plagued with alcohol related problems well into their adult lives, making relationships more difficult, causing intrapersonal conflicts, and limiting possible career opportunities (Wallace et al., 2006). Implications for School Counselors

\section{Role of the School Counselor}

Identify the possible warning signs of student substance abuse. School counselors can be the first line of defense in detecting a student's issue with substance abuse. Due to their accessibility to young people and continual work with school personnel, school counselors are well positioned to assist in substance abuse prevention and intervention efforts (Lambie \& Rokutani, 2002). Also, a counselor's contact with the adolescent's parents, teachers, peers, and coaches, and the young person can make it easier for him or her to identify possible warning signs of substance abuse and facilitate early intervention. Possible warning signs to look for include changes in an adolescents' behavior and moods; such things as changes in peer relations, a drop in grades, increased absences, and comments by teachers about changes in the adolescent's performance and behavior are all indicators of significant change and possible warnings signs for substance abuse (Lambie \& Rokutani, 2002). Substance use can have adverse effects on an adolescent's health, as well as social and physiological consequences. Therefore, it is extremely important for 
school counselors to be aware of possible warning signs in order to intervene as soon as possible (Watkins, Ellickson, Vaiana, \& Hiromoto, 2006).

Work with the students to establish a therapeutic relationship. Unlike other teachers whom may only interact with a student for a year, school counselors interact with students over the course of several years. This accessibility allows a counselor opportunities to create open rapport with students, creating a relationship with the students where they would feel comfortable sharing concerns. When a student comes to his or her counselor with concerns about alcohol use, it is important that the counselor not pass judgment, but rather provide support through empathic understanding and a sense of unconditional positive regard. Displaying these conditions will help the counselor create a safe and supportive environment, conducive for a therapeutic relationship (Lambie \& Rokutani, 2002). If a helping environment and therapeutic relationship is not established, a counselor will likely encounter resistance in his or her future interactions with the students, and interventions will likely be unsuccessful (Lambie \& Rokutani, 2002).

Support the family system to promote change. School counselors are in a position to support families and encourage parent involvement in student's lives. As stated earlier, students whose parents provide low involvement in their lives are at greater risk to engage in high-risk behaviors. According to Lambie \& Rokutani (2002), "Parents need increased contact with the school and with other parents to expand their understanding of how the school system works, what the school is trying to accomplish, and what resources are available to them to assist their child and themselves through the school system and community" (p. 8). There are many ways school counselors can assist parents on making this connection. Counselors can make information available to 
parents through newsletters or possibly provide parent education classes in which parents can both become informed about substance abuse prevention and the identification signs of substance abuse while making connections with other parents (Lambie \& Rokutani, 2002). In situations where students exhibit early warning signs of abuse, school counselors can request to consult with the parents. However, it is vitally important that a counselor be sensitive toward the family system, as it may be a contributing factor to the student's risky behavior (Beman, 1995). In such situations, the counselor will be given insight into the interactions between the parents and the student, and he or she will be able to provide the parents with valuable information on how systems outside the school setting affect behavior (Lambie \& Rokutani, 2002). Counselors are also able to provide crisis intervention and referral services (Lambie \& Rokutani, 2002).

Be a resource and liaison between the student, the family, the school, and community agencies and treatment programs. School counselors are able to act as both a resource and liaison by bridging the gap between the student and his or her family, community agencies, and the school (Lambie \& Rokutani, 2002). Counselors are in the position to adequately identify substance abuse and refer the families to various resources within the community to help assist with a student's recovery. In order for a counselor to confidently make a referral, it is important that he or she is aware of the agencies' goals, objectives and limitations; it is then that the counselor can most effectively serve his or her students (Lambie \& Rokutani, 2002). Also, as an attempt to make community agencies less intimidating, it may be beneficial for community agency personnel to visit the school and explain their services to the students. This action can be the first step in 
creating a collaborative relationship with the school and students (Lambie \& Rokutani, 2002).

\section{Effective Prevention and Treatment Interventions for Adolescents}

Adolescents' lives extend beyond school walls; therefore, many studies agree that in order for an alcohol prevention program to be effective it must be multifaceted, having multiple points of connection with the adolescent's life over multiple points in time (Bryant \& Zimmerman, 2002; Eaton, Forthofer, \& Zapata, 2004; Lambie \& Rokutani, 2002; Wolfsberg, 2007). School-based prevention programs are necessary, but they can only account for some of the risk factors influencing an adolescent's decision to drink (Wolfsberg, 2007). “Adolescents interact in their communities, consume our media culture (replete with pro-drinking and pro-drug use messages), and are members of complex peer and family systems where issues of belonging and connectedness are crucial" (Wolfsberg, 2007, p. 105). For this reason, an effective prevention program must take a comprehensive, integrated approach and address a range of risk factors at the personal and community levels (Eaton et al., 2004).

Programs incorporating a systems perspective and using multi-component strategies that include two or more strategies together (such as family and student programs or school and community activities) will have a greater impact on adolescent high-risk behavior (Lambie \& Rokutani, 2002; Wolfsberg, 2007). A program which recognizes a systems perspective will view an adolescent's behavior as a way of functioning within a system or unit, i.e. the adolescent's family or peer group. By taking this type of approach, the adolescent is not isolated, but rather viewed in a more holistic manner, taking into account the many risk factors that may influence his or her decision 
to use alcohol. This type of a preventative program would work to include a variety of influential people in the adolescent's life, including family members, school personnel, and community members, educating and encouraging these people to be positive role models and deterring the adolescent to engage in alcohol use.

Increasing a student's motivation and connection with the school community will also help to reduce his or her chance of using alcohol. According to Bryant and Zimmerman, 2002, "Enhancing motivation and academic achievement in schools are likely to promote the school community and reduce truancy among students" (p. 633). Students who find meaning in their classes and schoolwork are less likely to be truant and to engage in school crime and misbehavior (Bryant \& Zimmerman, 2002). This encourages teachers to motivate their students by creating challenging and engaging lessons. Not only will the students benefit academically, but it could help to reduce their chances of using drugs and alcohol in a social context.

Some schools have found success by implementing a mentor/mentee program. Such a program would match students with school personnel with whom they feel comfortable in order to help promote positive relationships within the school. Furthermore, the mentor would be encouraged to get to know his or her mentees on a personal basis, creating a context for the student to feel valued and appreciated within the school setting, hopefully increasing his or her motivation to attend and thus reduce his or her chances for using alcohol or other drugs.

\section{Conclusion}

With alcohol being the most commonly used drug among adolescents, it is important that school counselors are aware of the variables contributing to an 
adolescent's choice of whether or not to use and its effects. Furthermore, school counselors are in a unique position to intervene early in adolescent substance abuse, so being aware of common warning signs and effective interventions is essential in a counselor's success of dealing with the issue of alcohol.

There are many contributing factors to an adolescent's choice of whether or not to use alcohol. Many times an adolescent will feel indirect pressure from his or her peer group and messages from the media and society. Also, an adolescent is more likely to give in to these pressures when alcohol use is found acceptable among family members. Knowing this, schools can act in preventative ways by taking a strict anti-drug and substance abuse approach. However, if a student does not feel a strong connection with his or her school, these preventative efforts are often ignored and ineffective. Given all of this information, the anti-alcohol battle may seem daunting to school personnel, particularly school counselors. Yet, regardless of what a student chooses, the best antialcohol approach a counselor can take is building a trusting and supportive relationship with the student. When a student feels unconditional positive regard he or she begins to see his or her own potential. Counselors need to ignite a sense of self-pride in students by focusing on their positive qualities and see the students for who they are apart from the poor choices they may make. When a counselor is able to do this, he or she has taken the first step to aiding the student in substance abuse recovery. 


\section{References}

Arta, C.; Stafford, J. \& Tims, S. (2003). High school drinking and its consequences. Adolescence, 38, 56-79.

Barnett, J.; \& Miller, M. (2001). Adolescents' reported motivations to use or not to use alcohol or other drugs. The Social Studies, 92, (5), 209-212.

Beman, D. (1995). Risk factors leading to adolescent substance abuse. Adolescence, 30, 201- 208.

Brown, S.; Teufel, J.; Birch, D.; Raj, S.; Inzenberg, N.; Lyness, D.; \& Kancherla, V. (2007) Reported alcohol use and perceptions of use among early adolescents. American Journal of Health Studies, 22, (1).

Brown, E.; Catalano, R.; Fleming, C.; Haggerty, K.; \& Abbott, R. (2005). Adolescent substance use outcomes in the raising healthy children project: A two-part latent growth curve analysis. Journal of Consulting and Clinical Psychology, 73, (4), 699-710.

Bryant, A. \& Zimmerman, M. (2002). Examining the effects of academic beliefs and behaviors on changes in substance use among urban adolescents. Journal of Educational Psychology, 94, (3), 621- 637.

Cox, R.; Zhang, L. \& Johnson,W. (2007). Academic performance and substance use: Findings from a state survey of public high school students. The Journal of School Health, 77, (3), 109-115.

Diego, M.; Field, T.; \& Sanders, C. (2003). Academic performance, popularity, and depression predict adolescent substance use. Adolescence, 38, (149), 35-42. 
DuRant, R.; Rome, E.; Rich, M.; Allred, E.; Emans, J.; \& Woods, E. (1997). Tobacco and alcohol use behaviors portrayed in music videos: A content analysis. American Journal of Public Health, 87, (7), 1131-1135.

Eaton, D.; Forthofer, M.; \& Zapata, L. (2004). Factors related to alcohol use among $6^{\text {th }}$ through $10^{\text {th }}$ graders: The Sarasota County Demonstration Project. The Journal of School Health, 74, (3), 95- 104.

Henry, K.; \& Slater, M. (2007). The contextual effect of school attachment on adolescents' alcohol use. The Journal of School Health, 77, (2), 67-74.

Hingson, R.; Heeren, T.; \& Winter, M. (2006). Age at drinking onset and alcohol dependence: age at onset, duration, and severity. Archives of Pediatrics \& Adolescent Medicine, 160, (7),739-746.

Hoel, S.; Erikson, B.; Breidablik, H.; \& Meland, E. (2004). Adolescent alcohol use, psychological health and social integration. Journal of Public Health, 32, 361367.

Jaccard, J.; Blanton, H.; \& Dodge, T. (2005). Peer influences on risk behavior: An analysis of the effects of a close friend. Developmental Psychology, 41, (1), 135147.

Johnston, L.; O'Malley, P.; Bachman, J.; \& Schulenberg, J. (2006). Monitoring the Future national survey results on drug use, 1975- 2005: Volume 1, Secondary school students. Bethesda, MD: National Institute on Drug Abuse. Retrieved November 10, 2007, from http://monitoringthefuture.org/pubs/monographs/vol1_2005.pdf. 
Lambie, G.; \& Rokutani, L. (2002). A systems approach to substance abuse identification and intervention for school counselors. Professional School Counseling, 5, 5-9.

Papalia, D., Olds, S., Feldman, R. (2007). Human development (10 $0^{\text {th }}$ ed.). New York: McGraw-Hill.

Peele, S. (2006). Reducing harms from youth drinking. Journal of Alcohol and Drug Education, 50, (4), 67-87.

Power, T.; Stewart, C.; Hughes, S.; \& Arbona, C. (2005). Predicting patterns of adolescent alcohol use: A longitudinal study. Journal of Studies on Alcohol, 66, (1), 74- 78 .

Robinson, T; Chen, H.; \& Killen, J. (1998). Television and music video exposure and risk of adolescent alcohol use. Pediatrics, 102, (5), 54- 66.

Thorlindsson, T.; \& Bernburg, J. (2006). Peer groups and substance use: Examining the direct and interactive effect of leisure activity. Adolescence, 41, 321-339.

Vernon, A. (2004). Counseling children $\&$ adolescents ( $3^{\text {rd }}$ ed.). Denver, CO: Love Publishing.

Vernon, A. \& Clemente, R. (2005). Assessment and intervention with children and adolescents: Developmental and multicultural approaches. Alexandria, VA: American Counseling Association.

Wallace, S.; \& Fisher, C. (2006). Substance use attitudes among urban black adolescents: The role of parent, peer, and cultural factors. Journal of Youth and Adolescence, $1-12$. 
Watkins, K.; Ellickson, P.; \& Vaiana, M. (2006). An update on adolescent drug use:

What school counselors need to know. Professional School Counseling, 10, (2), $131-138$.

Wills, T.; Resko, J.; Ainetter, M.: \& Mendoza, D. (2004). Role of parent support and peer support in adolescent substance use: A test of mediated effects. Psychology of Addictive Behaviors, 18, (2), 122- 134.

Wolfsberg, J. (2007). Successful prevention of underage drinking and other drug use: An integrated approach. Independent School, 66, (2), 104-107. 